\title{
The Protection Effect of Topical Cocoa Extract on Cyclobutane Pyrimidine Dimer (CPD) Formation and Tissue Neutrophil in Mice Induced by Ultraviolet B
}

\author{
Utin Variantini ${ }^{1}$, Safruddin Amin ${ }^{1}$, Anni Adriani ${ }^{1}$, Idham Jaya Ganda ${ }^{2}$, Gemini Alam $^{3}$, \\ M. Husni Cangara ${ }^{4}$ \\ ${ }^{1}$ Department of Dermatology and Venereology, Medical Faculty, Hasanuddin University, Makassar, Indonesia \\ ${ }^{2}$ Department of Biostatistic, Faculty of Public Health, Hasanuddin University, Makassar, Indonesia; Department of Pediatric, Medical \\ Faculty, Hasanuddin University, Makassar, Indonesia \\ ${ }^{3}$ Department of Pharmacognosy, Faculty of Pharmacy, Hasanuddin University, Makassar, Indonesia \\ ${ }^{4}$ Department of Anatomical Pathology, Medical Faculty, Hasanuddin University, Makassar, Indonesia
}

Email address:

utin.variantini@gmail.com (U. Variantini)

\section{To cite this article:}

Utin Variantini, Safruddin Amin, Anni Adriani, Idham Jaya Ganda, Gemini Alam, M. Husni Cangara. The Protection Effect of Topical Cocoa Extract on Cyclobutane Pyrimidine Dimer (CPD) Formation and Tissue Neutrophil in Mice Induced by Ultraviolet B. American Journal of Clinical and Experimental Medicine. Vol. 4, No. 6, 2016, pp. 160-165. doi: 10.11648/j.ajcem.20160406.11

Received: September 18, 2016; Accepted: September 27, 2016; Published: October 19, 2016

\begin{abstract}
Ultraviolet (UV) radiation has dangerous effects on the skin that may cause multiple clinical and cellular effects, which will produce DNA damage characterized by formation of photoproducts such as cyclobutane pyrimidine dimer (CPD), and acute inflammation characterized by neutrophil infiltration in the skin tissues. Cocoa flavanols are natural anti inflammatory molecules that has a role in preventing cutaneous UV damage. The aims of this study are to assess protection effects of topical cocoa extract against formation of CPD and tissue neutrophils caused by ultraviolet B radiation. This study is a true experimental study using mice as animal model, conducted at animal laboratory of Hasanuddin University and Sentra Diagnostic Patologia Laboratory from April to Mei 2016. Total of samples were 30. Protection effects of CPD formation occur with application of $200 \mathrm{ppm}$ cocoa extract, with frequency of negative and weak CPD expression were $60 \%$ and $40 \%$, respectively. There was an increased in protection with application of $400 \mathrm{ppm}$ cocoa extract, with frequency of negative and weak CPD expression were $80 \%$ and $20 \%$, respectively, and there was decrease of protection with application of $800 \mathrm{ppm}$ cocoa extract, with frequency of negative and weak CPD expression were $40 \%$ and $60 \%$ respectively. The group which only exposed with UVB has higher mean of tissue neutrophils (mean=10,4), and groups with application of $400 \mathrm{ppm}$ and $800 \mathrm{ppm}$ cocoa extract have lowest mean of tissue neutrophils (mean=1,4). There was no significant differences between groups with application of $400 \mathrm{ppm}$ and $800 \mathrm{ppm}$ cocoa extract. The best protection effects on CPD formation and tissue neutrophil achieved with application $400 \mathrm{ppm}$ of cocoa extract.
\end{abstract}

Keywords: Cyclobutane Pyrimidine Dimer, Tissue Neutrophil, Ultraviolet B

\section{Introduction}

Ultraviolet radiation (UVR) is known to be one of the most important environmental hazard acting on the skin. [1] Nowadays, the level of UV radiation reaching the earth surface is increasing as a result of depletion of the stratospheric ozone, and climate change. [2] Ultraviolet radiation is a small component of the electromagnetic spectrum with a narrow band of radiation from $200-400 \mathrm{~nm}$. The UV spectrum is further divided into UVA1 (340-400 nm), UVA2 (320-340 nm), UVB (280-320 nm) and UVC (200-280 nm). The International Agency for Research on Cancer (IARC) classified UVR as a carcinogenic radiation to human. [3]

Although sun exposure is widely felt to induce a sense of well being, important for synthesis vitamin D3 and the setting of internal clocks, on the other hand, sunlight causes 
deleterious acute and chronic inflammatory skin reactions, skin cancer, and photoaging, and can elicit adverse reactions to certain drugs. [4] Exposure of the skin to UV radiation has multiple cellular and clinical effects, including an increase in skin cancer risk. UV light produces a type of DNA damage involving the generation of photoproducts, which are alterations in the structure of nucleotides. The major DNA photoproducts are cyclobutane pyrimidine dimers (CPDs) and 6,4-pyrimidine-pyrimidone. [5] UV irradiation-induced CPD formation leads to the release of immunosuppressive cytokines, such as IL-10, from keratinocytes. [6]

Several studies have documented that exposure of the skin to UV radiation results in immediate formation of CPDs in skin cells. Most of the UVB-induced CPDs were found in the epidermis, but some were detected in the dermis. The location of the damage depends on the ability of the UV radiation to penetrate the skin. It has been found that UV exposure of less than one minimal erythema dose is sufficient to cause DNA damage in target cells of human skin. [7]

The biologic effects of CPD formation comprise acute effects such as pigmentation (tanning) and erythema (sunburn), and the synthesis of vitamin D; immunosuppression as transient effect; and chronic exposure to UV radiation causes premature skin aging and increases the risk of skin cancer. [8] Erythema is the most visually apparent indicator of UV-induced skin inflammation. In histopathological examination of inflammation skin, dermal changes include early and persistent endothelial swelling, perivenular edema and degranulated mast cells. Neutrophils appear perivasculary shortly after UVB and the influx peaks at about 14 hours. A later mononuclear (macrophage) infiltrate persists at least 48 hours. [9]

Several studies have evaluated naturally botanical product, including polyphenols, for the prevention of UV-induced skin photodamage. Nichols and Katiyar (2010) have documented the efficacy of naturally occurring polyphenols, such as green tea polyphenols (GTPs), silymarin from milk thistle and proanthocyanidins from grape seeds (GSPs), against UVR-induced inflammation, oxidative stress, DNA damage and suppression of immune response. [7] Experimental study by Djawad, 2008, which evaluated protective effects of curcumin on photoproduct expression, apoptosis and epidermal hyperplasia after UVB exposure had documented the efficacy of curcumin in inhibiting indirect photoproduct formation and preventing permanent DNA damage, inhibiting apoptosis and protective effect on epidermal hyperplasia. [10]

Adriani (2014) had examined cocoa extract on mice exposed with UVB and evaluated $8-\mathrm{OHdG}$ photoproduct expression, PCNA, and hyperplasia. The study had documented a decreased of $8-\mathrm{OHdG}$ photoproduct expression, PCNA and hyperplasia after application of cocoa extract, the result showed that cocoa extract has protective effect on UVR. Several studies that evaluated photoprotection effect of cocoa extract have documented polyphenol on cocoa has an antioxidant effect that can protect body from reactive oxygen species (ROS) formation as a result of UVB exposure, but the efficacy in inhibiting direct photoproduct formation after UV exposure, CPD, is still unknown and there is no study that evaluated photoprotection effect of cocoa extract in inhibiting direct photoproduct formation and tissue neutrophil. [11]

Based on these literatures above, we conducted an experimental study to assess the protective effects of cocoa extract on CPD formation and tissue neutrophil as a marker of inflammation after UVB exposure.

\section{Material and Method}

\subsection{Study Design}

The study was a true animal experimental research design with control group, conducted in the Animal Laboratory of Hasanuddin University and Sentra Diagnostic Patologia Laboratory, Makassar, Indonesia from April to May 2016, after obtaining the approval from ethics committee of health research.

\subsection{Animals and UVB Radiation}

The samples were 30 mice that meet the criteria. The inclusion criteria were species of Swiss albino female mice, 6-9 weeks old, weighing 20-30g and healthy. They were housed in wire-topped plastic boxes and maintained at $25^{\circ} \mathrm{C}$ with 12 hours light, alternating with 12 hours dark. The skin of the mice were prepared with a hair removal cream about one week before the experiments. The sample that meet criteria were divided into 6 groups: control, UVB, ethanol+UVB, cocoa 200+UVB, cocoa 400+UVB, and cocoa 800+UVB. All mice at each group, except control, were exposed to UVB at a dose $450 \mathrm{~mJ} / \mathrm{cm}^{2}$ for 3 consecutive day, 30 minutes after topical application of cocoa extract and ethanol 96\%. All mice were sacrificed $1 \mathrm{~h}$ after UVB exposure on last day (day-3). Mid-dorsal skins of mice were excised, fixed in buffered formalin.

\subsection{Topical Solution}

Cocoa extract containing purified polyphenol with a concentration of $200 \mathrm{ppm}, 400 \mathrm{ppm}$, and $800 \mathrm{ppm}$ was made in the laboratory of pharmacognosy Phytochemical, Faculty of Pharmacy, Hasanuddin University. Cocoa extract of $0.5 \mathrm{ml}$ were applied to the dorsum of mice and spread with a gloved finger; the mice were held on their cage while the solution was absorbed into the skin before exposure with UVB.

\subsection{Immunohistochemical Staining of CPD}

All tissue samples were paraffin-embedded and formalin fixed for immunohistochemistry (IHC) evaluation for CPD. Then tissue cuts were prepared in $4 \mu \mathrm{m}$ thick using Leica 2125 RM microtom and placed on glassy slides. The used glasses were coated by poly-L-lysine. The slides were heated on hotplate then put into the incubator $30-40^{\circ} \mathrm{C}$ for 1 hour until dried. Then the samples were deparaffinized and put into xylol solution three times for 5 minutes each, rinse in the 
ethanol and alcohol $90 \%, 80 \%$, and $70 \%$ for 5 minutes each, the wash with distilled water. Inactivation of endogenous peroxidase using 3\% hydrogen peroxide and methanol for 15 minutes, rinse with aquadest for 5 minutes. Then, rinse in the antigen target retrieval solution and put into microwave for 30 minutes, then wash with aquadest. Drop the block protein sniper for 30 minutes, rinse with phosphate buffer saline (PBS) for 5 minutes. Then drop the primary anti-CPD antibody (Kamiya) for 1 hour, rinse with PBS. For the secondary antibody, drop the biotinylated goat antipolyvalent for 30 minutes, rinse with PBS. Drop the streptavidine-biotin for 20 minutes, rinse again with PBS twice for 5 minutes each. After staining, the slices were put in 3, 3-diaminobenzidine (DAB) and chromogen substrate which lead to detection of antigen with brown color, then rinse with distilled water. Counterstaining with Mayer haematoxyllin for 2 minutes. After all these steps, slides were examined by light microscopy. In a field with high magnification $(\times 400)$, all cells were counted. The area percentage of stained cells was multiplied by the stain intensity and scored as negative, weak, moderate, and strong.

Table 1. CPD immunohistochemistry scoring.

\begin{tabular}{lllll}
\cline { 1 - 2 } \% area & $\mathbf{0}$ & $\mathbf{1}$ & $\mathbf{2}$ & $\mathbf{3}$ \\
\cline { 1 - 2 } Intensity & 0 & 0 & 0 & 0 \\
1 & 0 & 1 & 2 & 3 \\
2 & 0 & 2 & 4 & 6 \\
3 & 0 & 3 & 6 & 9 \\
\hline
\end{tabular}

Note:

Area percentage of stained cells was scored as:

0 : no expression (no staining)

1: staining in $<25 \%$ of the cells

2: staining in $25-50 \%$ of the cells

3: staining in $>50 \%$ of the cells

Staining intensity was scored as:

0 : non staining

1: weak

2: moderate

3: strong

Final scoring of CPD expression was the result of multiplication of area

percentage with staining intensity score and classified as:

Negative: 0

Weak: 1-3

Moderate: 4-6

Strong: 7-9

\subsection{Hematoxylin \& Eosin Staining of Tissue Neutrophil}

Deparaffinize the section with flame the slide on burner and place in the xylene and repeat the treatment, hydrate the tissue section by passing through decreasing concentration of alcohol baths and water $(100 \%, 90 \%, 80 \%, 70 \%)$, stain in hematoxylin for 3-5 minutes, wash in running tap water until sections "blue" for 5 minutes or less, differentiate in $1 \%$ acid alcohol (1\% HCL in $70 \%$ alcohol) for 5 minutes, wash in running tap water until the sections are again blue by dipping in a alkaline solution followed by tap water wash,stain in $1 \%$ eosin $\mathrm{Y}$ for 10 minutes, wash in tap water for 1-5 minutes,dehydrate in increasing concentration of alcohols and clear in xylene, mount in mouting media, and observed under microscope. A five randomly selected fields per section from each mouse were analyzed with 400 times magnification. A total neutrophil count based on the average of neutrophils in that five fields.

\subsection{Statistical Analysis}

Statistically significant differences were tested using Kruskall-Wallis test in statistical programme for socials sciences (SPSS) version 22.0 with significancy value if $p<0.05$, and continued with post hoc test with Mann Whitney method if there is significance.

\section{Result}

This study was performed on 30 swiss albino mice that meet inclusion criteria and were randomly selected and grouped according to the treatment as describe above.

\subsection{Protection Effect of Cocoa Extract on CPD Expression}

Table 2 below shows the frequency of CPD expression according to treatment group. Frequency of strong and moderate CPD expression was found in both the UVB and ethanol+UVB groups, that is $40 \%$ and $60 \%$, respectively. Weak CPD expression was highest in cocoa $800+$ UVB group $(60 \%)$, and negative CPD expression was in control group $(100 \%)$.

Table 2. Frequency of CPD expression according to treatment group.

\begin{tabular}{|c|c|c|c|c|c|c|c|}
\hline & & & \multicolumn{4}{|c|}{ CPD expression } & \multirow{2}{*}{ Total } \\
\hline & & & Negative & Weak & Moderate & Strong & \\
\hline & \multirow{2}{*}{ UVB } & $\mathrm{n}$ & 0 & 0 & 3 & 2 & \multirow{2}{*}{5} \\
\hline & & $\%$ & $0 \%$ & $0 \%$ & $60 \%$ & $40 \%$ & \\
\hline & \multirow{2}{*}{$\begin{array}{l}\text { Ethanol + } \\
\text { UVB }\end{array}$} & $\mathrm{n}$ & 0 & 0 & 3 & 2 & \multirow{2}{*}{5} \\
\hline & & $\%$ & $0 \%$ & $0 \%$ & $60 \%$ & $40 \%$ & \\
\hline & \multicolumn{2}{|c|}{ Cocoa $200+n$} & 3 & 2 & 0 & 0 & \multirow{2}{*}{5} \\
\hline Treatmen & tUVB & $\%$ & $60 \%$ & $40 \%$ & $0 \%$ & $0 \%$ & \\
\hline \multirow[t]{6}{*}{ group } & Cocoa $400+$ & $\mathrm{n}$ & 4 & 1 & 0 & 0 & \multirow{2}{*}{5} \\
\hline & UVB & $\%$ & $80 \%$ & $20 \%$ & $0 \%$ & $0 \%$ & \\
\hline & Cocoa $800+$ & $\mathrm{n}$ & 2 & 3 & 0 & 0 & \multirow{2}{*}{5} \\
\hline & UVB & $\%$ & $40 \%$ & $60 \%$ & $0 \%$ & $0 \%$ & \\
\hline & \multirow{2}{*}{ Control } & $\mathrm{n}$ & 5 & 0 & 0 & 0 & \multirow{2}{*}{5} \\
\hline & & $\%$ & $100 \%$ & $0 \%$ & $0 \%$ & $0 \%$ & \\
\hline Total & & $\mathrm{N}$ & 14 & 6 & 6 & 4 & 30 \\
\hline
\end{tabular}

The protection effect of CPD occur with application of 200 ppm cocoa extract, with frequency of negative and weak CPD expression were $60 \%$ and $40 \%$, respectively. The protection effect increase with application of $400 \mathrm{ppm}$ cocoa extract, with frequency of negative and weak CPD expression were $80 \%$ and $20 \%$, respectively. In contrast, the protection decrease with application of 800 ppm cocoa extract, with frequency of negative and weak CPD expression were $40 \%$ and $60 \%$ respectively. 


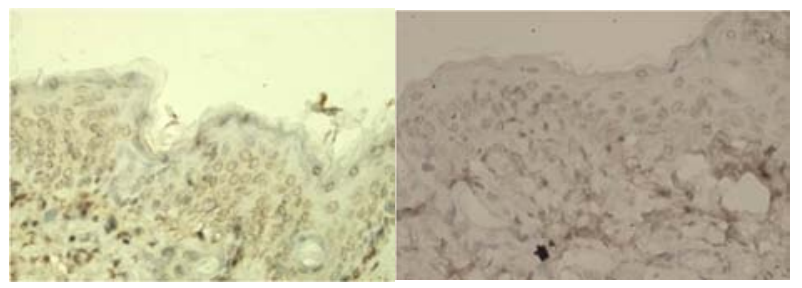

(a)

(b)

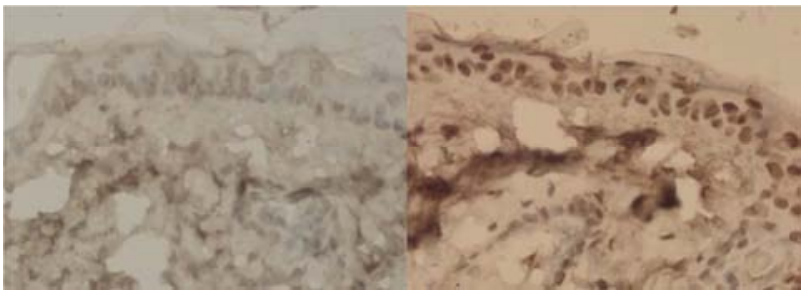

(c)

(d)

Figure 1. Immunohistochemistry stainning of CPD: (a) negative expression; (b) weak expression; (c) moderate expression; (d) strong expression.

\subsection{Protective Effect of Cocoa Extract on Tissue Neutrophil}

Table 3 below shows the comparison of mean tissue neutrophil according to treatment group, there were significant differences in mean tissue neutrophil $(p<0,05)$. The UVB group had a highest mean of tissue neutrophil $($ mean $=10,4)$, while the cocoa $400+\mathrm{UVB}$ and cocoa $800+\mathrm{UVB}$ groups has the lowest $($ mean $=1,4)$.

Table 3. The comparison of mean tissue neutrophil according to treatment group.

\begin{tabular}{|c|c|c|c|c|c|c|c|}
\hline \multirow{2}{*}{$\begin{array}{l}\text { Treatment } \\
\text { groups }\end{array}$} & \multirow{2}{*}{$\mathbf{n}$} & \multicolumn{5}{|c|}{ Tissue neutrophil* } & \multirow{2}{*}{$\mathbf{P}$} \\
\hline & & Minimun & Maximum & Median & Mean & SD & \\
\hline $\mathrm{UVB}^{(\mathrm{a})}$ & 5 & 9 & 13 & 10,0 & 10,4 & 1,67 & \multirow{5}{*}{0,00} \\
\hline Ethanol+UVB $^{(b)}$ & 5 & 9 & 11 & 10,0 & 9,8 & 0,84 & \\
\hline $\begin{array}{l}\text { Cocoa } \\
200+\mathrm{UVB}^{(\mathrm{c})}\end{array}$ & 5 & 2 & 4 & 3,0 & 3,0 & 0,71 & \\
\hline $\begin{array}{l}\text { Cocoa } \\
400+\mathrm{UVB}^{(\mathrm{d})}\end{array}$ & 5 & 1 & 2 & 1,0 & 1,4 & 0,55 & \\
\hline $\begin{array}{l}\text { Cocoa } \\
800+\mathrm{UVB}^{(\mathrm{e})}\end{array}$ & 5 & 1 & 2 & 1,0 & 1,4 & 0,55 & \\
\hline
\end{tabular}

Note:

$\mathrm{P}=$ Kruskal-Wallis

* The mean of tissue neutrophil in five fields of view with a 400 times magnification

In the control group there was no neutrophils

Post-Hoc Test (Mann Whitney method): (a):( b) $p=0.661$; (a):( c) $p=0.008$; (a):(d) $p=0.008$; (a):( e) $p=0,008 ;$ (b):( c) $p=0.008$; (b):(d) $p=0.008$; (b):(e) $p=0.008$; (c):(d) $p=0.013$; (c): (e) $p=0.013$; (d):(e) $p=1.000$

The post hoc test with Mann-Whitney method shows that groups having a significant difference are: UVB group vs. cocoa 200+UVB, cocoa 400+UVB, and cocoa 800+UVB group $(p<0,05)$; ethanol+UVB group vs. cocoa $200+U V B$, cocoa 400+UVB, and cocoa $800+U V B$ group $(p<0,05)$; cocoa $200+U V B$ group vs. cocoa $400+U V B$ group $(p<0,05)$; cocoa $200+\mathrm{UVB}$ vs. cocoa $800+\mathrm{UVB}(\mathrm{p}<0,05)$. There was no significant difference between cocoa $400+\mathrm{UVB}$ group and cocoa $800+$ UVB group $(\mathrm{p}>0,05)$.

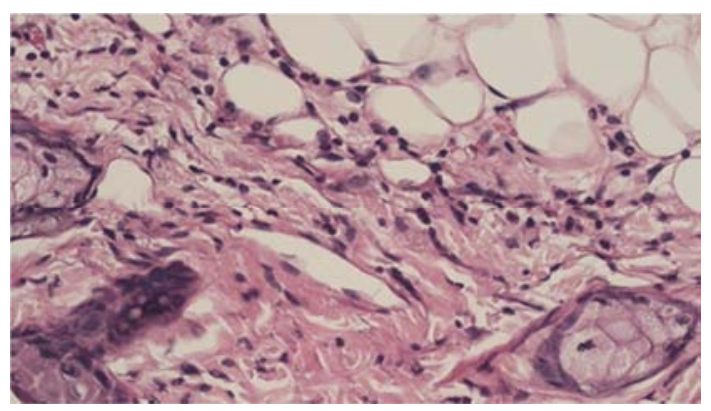

Figure 2. Tissue neutrophil (Hemaxtocillin \& Eosin Staining).

\section{Discussion}

CPD is the most common type of DNA lesion most occuring with both UVA and UVB exposure. Quantitative measurement of CPD is directly related to the amount of DNA damage. CPD is a type of DNA lesions most strongly implicated in all skin cancers induced by sunlight. [12].

In table 2 it is seen that the frequency of strong and moderate CPD expression most common in the UVB and ethanol+UVB groups, this suggests that exposure to UVB at a dose of $450 \mathrm{~mJ} / \mathrm{cm} 2$ for 3 consecutive days in mouse skin can cause DNA damage directly, with the formation of photoproduct CPD. Vink et al (1993) conducted an experimental study that detects thymine dimer in suprabasal and basal cell, 22 mice were irradiated with UVB chronically and on the first day of radiation, there is an increase in dimerspecific fluorescence, and the mean fluorescence reached a maximum after 3 day of irradiation, then it dropped to a lower level, around which it fluctuated for the subsequent days. They speculated that after the first exposure, the structure of chromatin becomes more open, and therefore the DNA more UV sensitive. [13]

In the ethanol+UVB group, application of ethanol $96 \%$ solution in mouse skin before UVB irradiation does not have a protective effect against the formation of CPD because in this group there was CPD formation with moderate to strong expression as seen in UVB group. In table 2 it is also seen that the application of $200 \mathrm{ppm}, 400 \mathrm{ppm}$ and 800 cocoa extract before UVB exposure may protect against CPD formation, the table showed that the application of cocoa extract decrease the percentage of strong CPD expression and even becomes negative. We suggest that application cocoa extract before UVB irradiation can decrease the expression of CPD due to the decrease of direct DNA damage. Polyphenols in cocoa is able to block the absorption of UVB light by DNA because most of natural polyphenol are pigments, typically yellow, red or purple, and can absorb UV radiation. Therefore, when applied topically, they can prevent penetration of the radiation into the skin. The radiation that polyphenols can absorb includes the entire UVB spectrum of wavelengths and part of the UVC and UVA. [7]

The protective effect against the formation of CPD was seen at $200 \mathrm{ppm}$ cocoa extract, the protective effect increased with increasing doses up to $400 \mathrm{ppm}$. However, at increasing doses to $800 \mathrm{ppm}$ the decreased protective effect was shown, 
so that the best protective effect of cocoa extract against the formation of CPD due to UVB irradiation was at a dose of $400 \mathrm{ppm}$. The decrease in the protective effect with increasing doses of the cocoa extract up to $800 \mathrm{ppm}$ appear linked to the polyphenol content itself, in which polyphenols are known as exogenous antioxidants which have functions such as "double-edged sword" in step "redox cell". In high concentrations, exogenous antioxidants also have pro-oxidant activity, wherein the type, dosage and matrix antioxidants may be determining factor impacting the balance between beneficial or deleterious effects of these natural compounds. Physiologic doses of exogenous antioxidants are required to maintain or re-establish redox homeostasis. [14]

Acute inflammation of the skin due to ultraviolet characterized by erythema, which is usually apparent 3-5 hours after UVB exposure, reaches maximum intensity at 1224 hours and generally resolves by 72 hours. The histological changes observed after UVB varies with the magnitude of the exposure dose. Neutrophils is an acute inflammatory cells predominantly appear perivascularly shortly after UVB exposure and the influx peaks at about 14 hours.[9] In this study, assessment of acute inflammation caused by the UVB exposure is done by calculating the mean of tissue neutrophil seen with histopathologic examination because the neutrophil is a type of PMN leukocytes which is easily to recognized and one of the main components that arise during acute inflammation. $[15,16]$ The research that evaluate the effects of consumption of high flavanol cocoa (HFC) as agent photoprotection by assessing the minimal erythema dose has previously been done, where the research conducted by Williams et al (2009) evaluating the potential photoprotection chocolate consumption (HFC) were assessed with the minimal erythema dose known that HFC consumption significantly protects the skin from the sun. [17]

In table 3 it is seen that there are significant differences in mean tissue neutrophil according to the treatment group ( $\mathrm{p}$ $<0.05$ ), where the UVB group has the highest mean of tissue neutrophils $($ mean $=10.4)$, while cocoa $400+$ UVB and cocoa $800+$ UVB groups have the lowest mean of tissue neutrophil $($ mean $=1.4)$. This suggests that UVB exposure on the mice skin at a dose of $450 \mathrm{~mJ} / \mathrm{cm} 2$ for 3 consecutive days can cause acute inflammation characterized by the infiltration of neutrophil cells in the skin tissues.

The ethanol+UVB group also has a high neutrophil cell counts (mean $=9.8)$, it is showed that the application of $96 \%$ ethanol solution in mouse skin before UVB irradiation does not have a protective effect on acute inflammation. Whereas in the group cocoa there are decrease in mean neutrophil cells in the skin tissue when compared with the UVB and ethanol+UVB groups, this shows that the cocoa extract have a protective effect against neutrophils infiltration in the skin tissue. Post hoc test with Mann Whitney method showed that increasing the dose of cocoa extract shown to provide better protection because there are significant differences between the mice groups were smeared with $200 \mathrm{ppm}$ and $400 \mathrm{ppm}$ cocoa extract, as well as between mice groups were smeared with 200 ppm and 800 ppm cocoa extract, although there was no significant difference between the mice groups that smeared with $400 \mathrm{ppm}$ and $800 \mathrm{ppm}$ cocoa extract. The 400 ppm cocoa extract is the best dose for protection against the formation of CPD and neutrophil tissue, although the data shown that the protection of the CPD, the best results seen in the $400 \mathrm{ppm}$ cocoa extract and decreased with increasing dose to $800 \mathrm{ppm}$, whereas on the protection of tissue neutrophil, the best protection dose is $400 \mathrm{ppm}$ and there is no increase or decrease the protection against tissue neutrophil with increasing dose to $800 \mathrm{ppm}$, we suggest it is due to the differences in the time to reach the highest levels, where CPD peaked is 1 hour after UVB exposure, whereas neutrophil 14 hours after UVB exposure to UVB. [9]

The study conducted by Nichols et al (2010), regarding the photoprotection of the skin by natural polyphenols with antiinflammatory activity, antioxidant and DNA repair mechanisms showed that the polyphenols contained in some natural ingredients such as green tea, grape seed, capable of inhibiting inflammation by inhibits UVB-induced expression of COX-2 and its prostaglandin metabolites. Topical treatment with GTPs prior UV exposure reduced the UVinduced hyperplastic response, myeloperoxidase activity and the number of infiltrating inflammatory leukocytes in the skin. [7]

Cocoa is a natural material that is rich in polyphenols, in this study showed that the application cocoa extract topically at a dose of $200 \mathrm{ppm}, 400 \mathrm{ppm}$ and $800 \mathrm{ppm}$ before UVB irradiation was able to reduce tissue neutrophil significantly in the dermis skin of mice, this indicates that cocoa extract has a protective effect against cell infiltration of neutrophils caused by exposure to UVB. We suggest that the decrease of tissue neutrophils were associated with a reduced CPD photoproduct formed. No formation of CPD or decrease the formation of CPD after rubbing cocoa extract also resulted in a decrease in pro-inflammatory cytokines so there is no cell infiltration of neutrophils in the skin tissue.

Absorption of UVB photons by chromophores in skin leads to the production of inflammatory mediators and cytokines that characterize the sunburn response. The action spectrum for erythema closely correlates with the absorption spectrum of DNA suggesting that DNA is one of the important chromophores and that DNA photoproducts initiate at least partially the biochemical pathways leading to UVinduced inflammation Until now, the biochemical pathways linking the DNA photoproducts with inflammatory mediators are still unclear. However, an action spectrum for TNF- $\alpha$ followed the DNA absorption spectrum suggesting formation of this proinflammatory cytokine is initiated by DNA photoproducts. [9]

Although it still needs some further research to evaluate the function of the polyphenols in the field of dermatology, some data from previous studies have shown the protective effects of polyphenols on the biochemical processes that are induced or mediated by UVR, suggesting that routine use of natural polyphenols both topically and orally may provide effective protection against UVR. [7] The ability of cocoa pytochemical to modulate critical biochemical functions 
makes cocoa a promising candidate for further dermatology applications, ranging from cosmetic wellness to the prevention of carcinogenesis. [18]

\section{Conclusion}

In this study, application of cocoa extract is effective in preventing UVB-induced CPD formation and tissue neutrophil. The $400 \mathrm{ppm}$ cocoa extract is the most effective in preventing $\mathrm{CPD}$ formation and tissue neutrophil due to UVB exposure.

\section{References}

[1] Reich A, Mędrek K. Effects of narrow band UVB (311 nm) irradiation on epidermal cells. Int J Mol Sci. 2013;14:8456-66.

[2] Li N-N, Deng L, Xiangan L-P, Liang Y-R. Photoprotective effect of tea and its extracts against ultraviolet radiationinduced skin disorders Trop J Pharm Res. 2014;13(3):475-83.

[3] Kozma B, Eide MJ. Photocarcinogenesis an epidemiologic perspective on ultraviolet light and skin cancer. Dermatol Clin. 2014;32:301-13.

[4] Kochevar IE, Taylor CR, Krutmann J. Fundamentals of cutaneous photobiology and photoimunology In: Goldsmith LA, Katz SI, Gilchrest BA, Paller AS, Leffell DJ, Wolf K, editors. Fitzpatrick's dermatology in general medicine. 8 ed. New York: McGraw-Hill; 2012. p. 1459-81.

[5] Runger TM, Kraemer KH. Genome instability, DNA repair, and cancer. In: Goldsmith LA, Katz SI, Gilchrest BA, Paller AS, Leffell DJ, Wolf K, editors. Fitzpatrick's dermatology in general medicine. 8 ed. New York: McGraw-Hill; 2012. p. 1748-62.

[6] Widyarini S. Protective effect of the isoflavone equol against DNA damage induced by ultaviolet radiation to hairless mouse skin. J Vet Sci. 2006;7(3):217-23.

[7] Nichols JA, Katiyar SK. Skin photoprotection by natural polyphenols: anti-inflammatory, anti-oxidant and DNA repair mechanisms. Arch Dermatol Res. 2010;302(2):1-11.
[8] Pastila R. Pastila, R. 2013. Effects of ultaviolet radiation on skin cell proteome. Rad Proteomics, 990, 121-127. Adv Exp Med Biol. 2013;990:121-7.

[9] Kochevar IE, Taylor CR, Krutmann J. Fundamentals of cutaneous photobiology and photoimmunology. In: Golsdsmith LA, Katz SI, Gilchrest BA, Paller AS, Leffel DJ, Wolf K, editors. Fitzpatrick's dermatology ini general medicine. New York: McGraw-Hill; 2012. p. 1459-81.

[10] Djawad K. Efek fotoprotektif kurkumin terhadap ekspresi CPD, 8-OHdG, apoptosis dan hiperplasia epidermis. Makassar: Hasanuddin University; 2008.

[11] Adriani A. Analisis ekspresi 8-OHdG, PCNA, dan hiperplasia epidermis pada kulit mencit yang mendapat ekstrak kakao topikal dan paparan UVB. Makassar: Hasanuddin University; 2014.

[12] DeHaven C, Hayden PJ, Amento A, Oidach J. DNA photoprotection conveyed by sunscreen. J Cosmet Dermatol. 2014;13:99-102.

[13] Vink AA, Berg RJW, Gruijl FRd, Lohman PHM, Roza L, Baan RA. Detection of thymine dimers in suprabasal and basal cells of chronically UV-B exposed hairless mice. $J$ Invest Dermatol. 1993;100(6):795-9.

[14] Bouayed J, Bohn T. Exogenous antioxidants-double-edged swords in cellular redox state. Oxid Med Cell Longev. 2010;3(4):228-37.

[15] Kolaczkowska E, Kubes P. Neutrophil recruitment and function in health and inflammation. Immunol. 2013;13:15972 .

[16] Kruger P, Saffarzadeh M, Weber ANR, Rieber N, Radsak M, Bernuth Hv, et al. Neutrophils: between host defence, immune modulation, and tissue injury. PLOS Pathogens 2015;12:1-23.

[17] Williams S, Tamburic S, Lally C. Eating chocolate can significantly protect the skin from UV light. $J$ Cosmet Dermatol. 2009;8:169-73.

[18] Scapagnini G, Davinelli S, Renzo LD, Lorenzo AD, Olarte $\mathrm{HH}$, Micali G, et al. Cocoa bioactive compounds: significance and potential for the maintenance of skin health. Nutrients. 2014;6:3202-13. 